\title{
The Measurement and Control of Chinese Administrative Expenses:
}

\section{Perspective into Administrative Expenses}

\author{
Xiangzhou He \\ Zhejiang University \\ Hangzhou 310028, China \\ E-mail: hexz1225@126.com
}

National Natural Science Foundation project: The empirical research of the cost of administrative expenses (70773065)

\begin{abstract}
Based on the reality of government administrative expenses, the article designed the theoretical models of government administrative expenses to predict the future cost of government----the basic criteria for administrative expenses, and came up with the corresponding proposes according to the basic analysis of Chinese government's expenses. The basic idea is: based on the actual expenditure of the Chinese Government's administrative expenses from 1978 to 2006 to establish the corresponding theoretical model and test, then according to 30 years of practice, to predict the basic bottom line the future expense of the Chinese government.
\end{abstract}

Keywords: The Chinese Government, Administrative Expenses, Predict and analyze

Generally speaking, The so-called government cost, is the negative effects brought to the community and the public by the government in the governance of the community or in public management activities (including all types of public projects decision-making, management processes, policy development, etc.), which can be controlled through governmental organizations or the Civil personal initiative. The governmental costs is a huge system, including tangible and intangible costs, marginal costs, decision-making costs, opportunity costs and accounting costs, explicit and implicit costs, incremental costs and sunk costs, and so on. So the scope of governmental costs is very broad, and different concepts of costs have different problems to study. This article specifically focused on the governmental expenses since 1978, and on the basis of research and theoretical model, forecast the scale of future costs of the Chinese government, then proposed advices on controlling government expenses.

\section{Basis of the Research: the Basic Information of Chinese Government Expenditure during 1978 and 2006}

In order to facilitate the research budget for the administrative costs of research, we can determine the basic conditions of administrative expenses. Generally speaking, financial conditions are prerequisite for the administrative costs, at the same time, it is also closely related to the total financial expenditure, and time is the inevitable element that socio-economic development should include. Actually, there are many variables that can influence administrative expenses, but the most important and basic variables are financial revenue and basic expenditure. Here, our assumptions are from the detailed information on the actual expenditures of China since 1978, thus making the whole research process built on the basis of empirical analysis. Table 1 is the actual implementation of budget cost of China from 1978 to 2006 , and the whole research process is based on the actual information (hard expenditure targets).

Insert Table 1 Here

\section{The Set of Prediction Model}

\subsection{Basic Analysis}

According to the information in Table 1, We chose to establish multiple linear regression model with criteria of application of least squares. Based on the relevant circumstance of the variables, we assume that financial income and total financial expenditure are the cost of the dependent variables, i.e.

$\mathrm{X} 1$ represents fiscal revenue, $\mathrm{X} 2$ represents the total financial expenditure, $\mathrm{t}$ represents time, $\mathrm{y}$ refers to the dependent variable---Administrative Expenses. 
According to relevant experience and knowledge, there are more than one variable that can influence the financial expenditure, we should consider using least-squares criteria to establish multiple linear regression model.

From Table 1, we can see that only the financial expenditure, financial revenue, the administrative cost are related, and the other set of data from area transformed from these three. Therefore, we only use administrative expenditure (y) as the dependent variable, the financial income $(\mathrm{x} 1)$ and the total expenditure $(\mathrm{x} 2)$ to establish the dual variable linear regression.

\subsection{According to whether plot has the linear regression to establish relation-model}

1) Based on matlab, we can get the plot of $\mathrm{y}$ and $\mathrm{x} 1, \mathrm{x} 2$ :

First list the data collection of $\mathrm{y}$ and $\mathrm{x}$, i.e. Table 2 is the data collection of dependent variable $\mathrm{y}$

Insert Table 2, Table 3, Table 4, Table 5, Table 6, Table 7 Here.

Insert Figure 1, Figure 2 Here.

From these two plots, we can clearly see that there are good linear relationships between y and $\mathrm{x} 1, \mathrm{x} 2$.

2) Establish the p-linear regression model between y and $x_{1}, x_{2}, \cdots x_{p}$

Assume that the linear relationship between them is:

$$
y=\beta_{0}+\beta_{1} x_{1}+\cdots+\beta_{p} x_{p}+\varepsilon
$$

$x_{1}, x_{2}, \cdots x_{p}$ in the equation are the general variables that can be accurately measured or controlled, $\mathrm{y}$ is the random variable that can be observed, $\beta_{0}, \beta_{1}, \beta_{2}$ is the unknown parameters, $\varepsilon$ is the random error that id subject to the unpredictable distribution, we got $\mathrm{n}$ groups of independent observations (sample)

$$
\left(y_{i}, x_{i 1}, \cdots x_{i p}\right), i=1,2, \cdots 29
$$

Thus,from equation (1), we know y1 has a data structure :

$$
y_{i}=\beta_{0}+\beta_{i 1} x_{1}+\cdots+\beta_{p} x_{i p}+\varepsilon_{i}, \quad i=1,2, \cdots 29
$$

All of these $\varepsilon_{1}, \varepsilon_{2}, \cdots \varepsilon_{29}$ are independent, and all are subject to $N\left(0, \sigma^{2}\right)$. This is the p-linear regression model. About the p-linear regression model, we will examine several issues below:

First, according to samples to estimate unknown parameters $\beta_{0}, \beta_{1}, \cdots, \beta_{p}, \sigma^{2}$ to establish relations between y and $x_{1}, x_{2}, \cdots x_{p}$ (often known as the regression equation).

Second, test the credibility of the resultant relationship.

Third, test whether the variables $x_{1}, x_{2}, \cdots x_{p}$ have a significant effecton the indicator.

3) Parameter estimates

First of all, let's discuss how to use the (2) to estimate $\beta_{0}, \beta_{1}, \cdots, \beta_{p}, \sigma^{2}$,the parameters in (1).Suppose $\beta_{0}, \beta_{1}, \cdots, \beta_{p}$ as $\hat{\beta}_{0}, \hat{\beta}_{1}, \cdots, \hat{\beta}_{p}$, then we can get a $\mathrm{p}$-linear regression equation:

$$
\hat{y}=\hat{\beta_{0}}+\hat{\beta}_{1} x_{1}+\cdots+\hat{\beta}_{p} x_{p}
$$

That (4) is the p-linear regression equation.On (2) in each sample $\left(x_{i 1}, \cdots x_{i p}\right)$, from (4), we can obtain the corresponding value:

$$
\hat{y}_{i}=\hat{\beta}_{0}+\hat{\beta}_{1} x_{i 1}+\cdots+\hat{\beta}_{p} x_{i p}
$$

The $y_{i}$ got by (5) is the return of value (in some cases, also known as predictive value, the value of fitting, etc.),we hope that by the estimating the regression equation set by $\hat{\beta}_{0}, \hat{\beta}_{1}, \cdots, \hat{\beta}_{p}$, we can make all the deviations to the minimum, according to least squares principle, which calls for 


$$
\min _{\beta_{0}, \beta_{1}, \cdots, \beta_{p}} \sum_{i=1}^{n}\left(y_{i}-\beta_{0}-\beta_{1} x_{i 1}-\cdots-\beta_{p} x_{i p}\right)^{2}=\sum_{i=1}^{n}\left(y_{i}-\hat{\beta}_{0}-\hat{\beta}_{1} x_{i 1}-\cdots-\hat{\beta}_{p} x_{i p}\right)^{2}
$$

Therefore, we only ask that $Q\left(\beta_{0}, \beta_{1}, \cdots, \beta_{p}\right)=\sum_{i=1}^{n}\left(y_{i}-\beta_{0}-\beta_{1} x_{i 1}-\cdots-\beta_{p} x_{i p}\right)^{2}$ to the minimal $\beta_{0}, \beta_{1}, \cdots, \beta_{p}$. As $\mathrm{Q}$ is a non-negative quadratic of $\beta_{0}, \beta_{1}, \cdots, \beta_{p}$, there must be the existence of its minimum. According to the calculus theory, the first order partial derivatives of $\mathrm{Q}$ to $\beta_{0}, \beta_{1}, \cdots, \beta_{p}$ is 0 .

$$
\left\{\begin{array}{c}
\frac{\partial Q}{\partial \beta_{0}}=-2 \sum_{i=1}^{n}\left(y_{i}-\beta_{0}-\beta_{1} x_{i 1}-\cdots-\beta_{p} x_{i p}\right)=0 \\
\frac{\partial Q}{\partial \beta_{j}}=-2 \sum_{i=1}^{n}\left(y_{i}-\beta_{0}-\beta_{1} x_{i 1}-\cdots-\beta_{p} x_{i p}\right) x_{i j}=0 \\
j=1,2, \cdots p
\end{array}\right.
$$

So we can get a linear equations about $\beta_{0}, \beta_{1}, \cdots, \beta_{p}$

$$
\left\{\begin{array}{l}
n \beta_{0}+\sum_{i=1}^{n} x_{i 1} \beta_{1}+\cdots+\sum_{i=1}^{n} x_{i p} \beta_{p}=\sum_{i=1}^{n} y_{i} \\
\sum_{i=1}^{n} x_{i 1} \beta_{0}+\sum_{i=1}^{n} x_{i 1}{ }^{2} \beta_{1}+\cdots+\sum_{i=1}^{n} x_{i 1} x_{i p} \beta_{p}=\sum_{i=1}^{n} x_{i 1} y_{i} \\
\cdots \ldots \ldots \cdots \\
\sum_{i=1}^{n} x_{i p} \beta_{0}+\sum_{i=1}^{n} x_{i p} x_{i 1} \beta_{1}+\cdots+\sum_{i=1}^{n} x_{i p}{ }^{2} \beta_{p}=\sum_{i=1}^{n} x_{i p} y_{i}
\end{array}\right.
$$

So (6) is the regular equations, and the solutions known as the least-squares estimation of $\beta_{0}, \beta_{1}, \cdots, \beta_{p}$

(6) is available in the form of a simple matrix. So

$$
X=\left(\begin{array}{cccc}
1 & x_{11} & \cdots & x_{1 p} \\
1 & x_{21} & \cdots & x_{2 p} \\
\cdots & \cdots & \cdots & \cdots \\
1 & x_{n 1} & \cdots & x_{n p}
\end{array}\right), \quad Y=\left(\begin{array}{c}
y_{1} \\
y_{2} \\
\vdots \\
y_{n}
\end{array}\right), \quad \beta=\left(\begin{array}{c}
\beta_{0} \\
\beta_{1} \\
\vdots \\
\beta_{p}
\end{array}\right)
$$

If we set (6) as the coefficient matrix A, the constant matrix as $\mathrm{B}$, then $\mathrm{A}$ is $\mathrm{XX}, \mathrm{B}$ is $\mathrm{XY}$ :

$$
\begin{aligned}
X^{\prime} X & =\left(\begin{array}{cccc}
1 & 1 & \cdots & 1 \\
x_{11} & x_{21} & \cdots & x_{n 1} \\
\cdots & \cdots & \cdots & \cdots \\
x_{1 p} & x_{2 p} & \cdots & x_{n p}
\end{array}\right)\left(\begin{array}{cccc}
1 & x_{11} & \cdots & x_{1 p} \\
1 & x_{21} & \cdots & x_{2 p} \\
\cdots & \cdots & \cdots & \cdots \\
1 & x_{n 1} & \cdots & x_{n p}
\end{array}\right) \\
& =\left(\begin{array}{cccc}
n & \sum_{i=1}^{n} x_{i 1} & \cdots & \sum_{i=1}^{n} x_{i p} \\
\sum_{i=1}^{n} x_{i 1} & \sum_{i=1}^{n} x_{i 1}{ }^{2} & \cdots & \sum_{i=1}^{n} x_{i 1} x_{i p} \\
\cdots & \cdots & \cdots & \cdots \\
\sum_{i=1}^{n} x_{i p} & \sum_{i=1}^{n} x_{i p} x_{i 1} & \cdots & \sum_{i=1}^{n} x_{i p}{ }^{2}
\end{array}\right)=A
\end{aligned}
$$




$$
X^{\prime} Y=\left(\begin{array}{cccc}
1 & 1 & \cdots & 1 \\
x_{11} & x_{21} & \cdots & x_{n 1} \\
\cdots & \cdots & \cdots & \cdots \\
x_{1 p} & x_{2 p} & \cdots & x_{n p}
\end{array}\right)\left(\begin{array}{c}
y_{1} \\
y_{2} \\
\vdots \\
y_{n}
\end{array}\right)=\left(\begin{array}{c}
\sum_{i=1}^{n} y_{i} \\
\sum_{i=1}^{n} x_{i 1} y_{i} \\
\vdots \\
\sum_{i=1}^{n} x_{i p} y_{i}
\end{array}\right)=B
$$

Hence, use the form of matrix to show (6) is:

$$
X^{\prime} X \beta=X^{\prime} Y
$$

$\mathrm{X}$ is known as the matrix structure, showing the structure of the mathematical expectation of $\mathrm{Y} . A=X^{\prime} X$ is the coefficient matrix of formal equations, $B=X^{\prime} Y$ is the constant matrix of formal equations. In the regression analysis, there usually exists $A^{-1}$, then the least square estimates can be expressed as:

$$
\hat{\beta}=\left(X^{\prime} X\right)^{-1} X^{\prime} Y
$$

When we obtained the least-squares estimation $\hat{\beta}$, we can create a regression equation $\hat{y}=\hat{\beta_{0}}+\hat{\beta}_{1} x_{1}+\cdots+\hat{\beta}_{p} x_{p}$

So we can use it to predict and control the targets. For example, given any set of $\left(x_{01}, x_{02}, \cdots x_{0 p}\right)$, the values of variables $x_{1}, x_{2}, \cdots x_{p}$, based on $\hat{y}=\hat{\beta_{0}}+\hat{\beta}_{1} x_{1}+\cdots+\hat{\beta_{p}} x_{p}$, we can get the corresponding forecast:

$\hat{y}_{0}=\hat{\beta_{0}}+\hat{\beta}_{1} x_{01}+\cdots+\hat{\beta}_{p} x_{0 p}$

Besides, in order to understand the accuracy of forecast and control the need of production, usually we need to seek estimates of $\sigma^{2}$.

In order to estimate $\sigma^{2}$, let's first introduce several terms. The margin between the measured value $y_{i}$ and the return value $y_{i}, y_{i}-\hat{y}_{i}$, is the residual value, and

$$
\tilde{Y}=Y-\hat{Y}=Y-X \hat{\beta}=\left[I_{n}-X\left(X^{\prime} X\right)^{-1} X^{\prime}\right] Y
$$

is Residual Vector, and

$$
\begin{aligned}
& S_{e}=\sum_{i=1}^{n}\left(y_{i}-\hat{y}_{i}\right)^{2}=\tilde{Y}^{\prime} \tilde{Y}=(Y-X \hat{\beta})^{\prime}(Y-X \hat{\beta}) \\
&=Y^{\prime} Y-\hat{\beta} X^{\prime} Y=Y^{\prime}\left[I_{n}-X\left(X^{\prime} X\right)^{-1} X^{\prime}\right] Y
\end{aligned}
$$

is the remaining square feet (or square and residual), the equations in (9) is just all kinds of different expressions.

In order to give unbiased estimates of $\sigma^{2}$, let's first prove a theorem:

Theorem

$$
E\left(S_{e}\right)=(n-p-1) \sigma^{2}
$$

Proof: $\quad \because S_{e}=\sum_{i=1}^{n}\left(y_{i}-\hat{y}_{i}\right)^{2}=\tilde{Y}^{\prime} \tilde{Y}=(Y-X \hat{\beta})^{\prime}(Y-X \hat{\beta})$

$$
=Y^{\prime} Y-\hat{\beta} X^{\prime} Y=Y^{\prime}\left[I_{n}-X\left(X^{\prime} X\right)^{-1} X^{\prime}\right] Y
$$

$\therefore \quad E\left(S_{e}\right)=E\left(\tilde{Y}^{\prime} \tilde{Y}\right)=E\left(\operatorname{tr} \tilde{Y}^{\prime} \tilde{Y}\right)=E\left(\operatorname{tr} \tilde{Y} \tilde{Y}^{\prime}\right)=\operatorname{tr} E\left(\tilde{Y} \tilde{Y}^{\prime}\right)$ 
$\because \tilde{Y}=Y-\hat{Y}=Y-X \hat{\beta}=\left[I_{n}-X\left(X^{\prime} X\right)^{-1} X^{\prime}\right] Y$

$\therefore E \tilde{Y}=E(Y-X \hat{\beta})=E\left[Y-X\left(X^{\prime} X\right)^{-1} X^{\prime} Y\right]=X \beta-X\left(X^{\prime} X\right)^{-1} X^{\prime} \cdot X \beta=0$

$\therefore$

$$
\begin{aligned}
E\left(\tilde{Y} \tilde{Y}^{\prime}\right)=D & (\tilde{Y})=D\left[\left(I_{n}-X\left(X^{\prime} X\right)^{-1} X^{\prime}\right) Y\right] \\
& =\left[I_{n}-X\left(X^{\prime} X\right)^{-1} X^{\prime}\right] D(Y)\left[I_{n}-X\left(X^{\prime} X\right)^{-1} X^{\prime}\right] \\
= & {\left[I_{n}-X\left(X^{\prime} X\right)^{-1} X^{\prime}\right]\left[I_{n}-X\left(X^{\prime} X\right)^{-1} X^{\prime}\right] \sigma^{2} } \\
& =\sigma^{2}\left[I_{n}-X\left(X^{\prime} X\right)^{-1} X^{\prime}\right]
\end{aligned}
$$

Put it into

$$
\begin{aligned}
E\left(S_{e}\right) & =\operatorname{tr} \sigma^{2}\left[I_{n}-X\left(X^{\prime} X\right)^{-1} X^{\prime}\right] \\
& =\sigma^{2}\left(n-t r I_{p+1}\right)=\sigma^{2}(n-p-1)
\end{aligned}
$$

That's all.

From $E\left(S_{e}\right)=(n-p-1) \sigma^{2}$, we can see

$$
\hat{\sigma}^{2}=\frac{S_{e}}{n-p-1}
$$

is unbiased estimate of $\sigma^{2}$.

Let's go back to the issues we are discussing, we want to establish the dual linear regression between administrative expenditure and financial revenue and financial expenditure. We use matrix form to write its formal equations. First write out XY matrix:

$$
X=\left(\begin{array}{rrr}
1 & x_{11} & x_{12} \\
1 & x_{21} & x_{22} \\
\vdots & \vdots & \vdots \\
1 & x_{n 1} & x_{n 2}
\end{array}\right) \quad Y=\left(\begin{array}{c}
y_{1} \\
y_{2} \\
\vdots \\
y_{n}
\end{array}\right)
$$

then

$$
X^{\prime} X=\left(\begin{array}{ccc}
n & \sum_{i=1}^{n} x_{i 1} & \sum_{i=1}^{n} x_{i 2} \\
\sum_{i=1}^{n} x_{i 1} & \sum_{i=1}^{n} x_{i 1}{ }^{2} & \sum_{i=1}^{n} x_{i 1} x_{i 2} \\
\sum_{i=1}^{n} x_{i 2} & \sum_{i=1}^{n} x_{i 1} x_{i 2} & \sum_{i=1}^{n} x_{i 2}{ }^{2}
\end{array}\right), X^{\prime} Y==\left(\begin{array}{c}
\sum_{i=1}^{n} y_{i} \\
\sum_{i=1}^{n} x_{i 1} y_{i} \\
\sum_{i=1}^{n} x_{i 2} y_{i}
\end{array}\right)
$$

So, From $\hat{\beta}=\left(X^{\prime} X\right)^{-1} X^{\prime} Y$, we can get a formal equations:

$$
\left\{\begin{array}{l}
n \beta_{0}+\sum_{i=1}^{n} x_{i 1} \beta_{1}+\sum_{i=1}^{n} x_{i 2} \beta_{2}=\sum_{i=1}^{n} y_{i} \\
\sum_{i=1}^{n} x_{i 1} \beta_{0}+\sum_{i=1}^{n} x_{i 1}{ }^{2} \beta_{1}+\sum_{i=1}^{n} x_{i 1} x_{i 2} \beta_{2}=\sum_{i=1}^{n} x_{i 1} y_{i} \\
\sum_{i=1}^{n} x_{i 2} \beta_{0}+\sum_{i=1}^{n} x_{i 1} x_{i 2} \beta_{2}+\sum_{i=1}^{n} x_{i 2}{ }^{2} \beta_{2}=\sum_{i=1}^{n} x_{i 2} y_{i}
\end{array}\right.
$$

$x_{i 1}, x_{i 2}$ refer to financial income and financial expenditure from 1978 to 2006, $n=29$, 
A direct solution is:

By regular equations (11), we know that:

$$
\hat{\beta}_{0}=\bar{y}-\hat{\beta}_{1} \bar{x}_{1}-\hat{\beta}_{2} \bar{x}_{2}
$$

and $\bar{y}=\frac{1}{n} \sum y_{i}, \bar{x}_{1}=\frac{1}{n} \sum x_{i 1}, \bar{x}_{2}=\frac{1}{n} \sum x_{i 2}$, put it into the second and third equations of (11), we can get a binary equations about $\hat{\beta_{1}}, \hat{\beta}$

$$
\left\{\begin{array}{l}
\sum\left(x_{i 1}^{2}-x_{i 1} \bar{x}_{1}\right) \hat{\beta}_{1}+\sum\left(x_{i 1} x_{i 2}-x_{i 1} \bar{x}_{2}\right) \hat{\beta}_{2}=\sum\left(y_{i}-\bar{y}\right) x_{i 1} \\
\sum\left(x_{i 1} x_{i 2}-x_{i 2} \bar{x}_{1}\right) \hat{\beta}_{1}+\sum\left(x_{i 2}{ }^{2}-x_{i 2} \bar{x}_{2}\right) \hat{\beta}_{2}=\sum\left(y_{i}-\bar{y}\right) x_{i 2}
\end{array}\right.
$$

Thus we can get thee values of $\hat{\beta}_{1}, \hat{\beta}_{2}$.

$$
\begin{gathered}
\text { Let's put } l_{11}=\sum\left(x_{i 1}{ }^{2}-x_{i 1} \bar{x}_{1}\right) \quad l_{12}=\sum\left(x_{i 1} x_{i 2}-x_{i 1} \bar{x}_{2}\right) \quad l_{01}=\sum\left(y_{i}-\bar{y}\right) x_{i 1} \\
l_{21}=\sum\left(x_{i 1} x_{i 2}-x_{i 2} \bar{x}_{1}\right) \quad l_{22}=\sum\left(x_{i 2}{ }^{2}-x_{i 2} \bar{x}_{2}\right) \quad l_{02}=\sum\left(y_{i}-\bar{y}\right) x_{i 2}
\end{gathered}
$$

So

$$
\left\{\begin{array}{l}
\hat{\beta}_{0}=\bar{y}-\hat{\beta}_{1} \bar{x}_{1}-\hat{\beta}_{2} \bar{x}_{2} \\
\hat{\beta}_{1}=\frac{l_{01} l_{22}-l_{02} l_{12}}{l_{11} l_{22}-l_{12} l_{21}} \\
\hat{\beta}_{2}=\frac{l_{02} l_{11}-l_{01} l_{21}}{l_{11} l_{22}-l_{12} l_{21}}
\end{array}\right.
$$

After we got $\hat{\beta}_{0}, \hat{\beta}_{1}, \hat{\beta}_{2}$, first, from

$$
S_{e}=\sum_{i=1}^{n}\left(y_{i}-\hat{y}_{i}\right)^{2}=\tilde{Y}^{\prime} \tilde{Y}=(Y-X \hat{\beta})^{\prime}(Y-X \hat{\beta})=Y^{\prime} Y-\hat{\beta} X^{\prime} Y=Y^{\prime}\left[I_{n}-X\left(X^{\prime} X\right)^{-1} X^{\prime}\right] Y
$$

to get the value of $S_{e}$, then using $\hat{\sigma}^{2}=\frac{S_{e}}{n-3}$ to get the value of $\hat{\sigma}^{2}$.

As the data is from 1978 to 2006, 29 years' data to calculate, it's difficult to calculate. However, Matlab provides a tool for calculating the linear regression, so we can get a relatively accurate estimate with Can be minus a lot of red tape can be more accurate calculation of the estimate without much tedious calculations. In order to make the calculation more accurate, we narrow the data in each group by 10 times, i.e. each data is multiplied by 0.1 , in this way, the use of statistics toolbox can help to get the initial regression equation.

Procedures are as follows:

Firstly, list the data collection of $\mathrm{y}$ and $\mathrm{x} 1, \mathrm{x} 2$, respectively, to Table 8, Table 9, and Table 10:

Insert Table 8, Table 9, Table 10, Table 11 Here

The results include regression coefficient $b=\left(\beta_{0}, \beta_{1}, \beta_{2}\right)=(-141.6291,-0.2704,0.4182)$, and there are no zero points in the confidence interval; residuals and confidence interval; Statistical variables including four test statistics: the square of the correlation coefficient $R^{2}$, supposing testing statistics $F$, the corresponding probability $p$, the value of $s^{2}$.Therefore, we have a preliminary regression equation:

$$
\hat{y}=-141.6291-0.2504 x_{1}+0.4538 x_{2}
$$

4) Judgement of the model from the results

There are no zero points in confidence interval and residuals in the vicinity of zero point both show that the model is 
relatively good. Then test the model with statistics $R^{2} F p$.

a. Evaluation of the correlation coefficient: generally, if the absolute value of correlation coefficient is between $0.8 \sim 1$, it can be determined that can the variables and return variable have a strong linear correlation. The absolute value for $R^{2}$ in this model is 1 , showing a relatively strong linear correlation.

b. $F$ test: when $F>F_{1-\alpha}(m, n-m-1)$, we can say there is a significant linear relationship between dependent variableness and variable $x_{1}, x_{2}$; or the relationship is not so significant. In the model, $F=2005.8$

Larger than $F_{1-\alpha}(2,22)=3.4434$ (Check the distribution table of $\mathrm{F}$ or enter orders finv $(0.95,2,22)$ ).

c. $p$ value test: if $p<\alpha$ (the pre-set the significant level), then there is a significant linear relationship between dependent variableness and variable. The output result of the model is $p<0.0001$, obviously fit $p<\alpha=0.05$.

The above three methods of statistical inference is consistent with the results, showing that there is a significant linear relationship between y dependent variableness and variable $x_{1}, x_{2}$, so the regression model is applicable. The smaller $s^{2}$ is, the better, this is a reference when improving the model.

\section{Forecast on Future Administrative Costs of Chinese Government}

To test the accuracy of the model, we selected 2008, 2020 and 2050 to simulate the forecast. To get the administrative expenses of 2008 to 2020 and 2050, ourideais to treat time as an independent variable, the financial income and financial expenditures as dependent variables, through Matlab toolbox as a linear or nonlinear fitting we can expect the year's revenue and expenditure, and by a model in the regression equation, administrative expenses of the year can be expected. Likewise, we use Matlab toolbox for a time and financial revenue and expenditure of the plot, and find a quadratic function of a relationship, so we use quadratic polynomial to fit their relationship.

3.1 Forecast Procedures

1) Establish M Documents

function $y h a t=\operatorname{model}($ beta $0, x)$

$\mathrm{a}=\operatorname{beta} 0(1)$;

$\mathrm{b}=\operatorname{beta} 0(2)$;

$\mathrm{c}=\operatorname{beta0}(3)$;

$\mathrm{x} 2=\mathrm{x}(:, 2)$;

$\mathrm{t}=\mathrm{x}(:, 1)$;

yhat $=\mathrm{a}+\mathrm{b} * \mathrm{t}+\mathrm{c} * \mathrm{t} . \wedge 2$;

2) Establish Procedures and Forecast

\begin{tabular}{|c|c|c|}
\hline$=[1978$ & 1132.26 & 1122.09 \\
\hline 1979 & 966.61 & 1281.37 \\
\hline 1980 & 1159.93 & 1228.83 \\
\hline 1981 & 1415.15 & 1426.22 \\
\hline 1982 & 1478.68 & 1428.32 \\
\hline 1983 & 1519.36 & 1556.88 \\
\hline 1984 & 1563.76 & 1647.49 \\
\hline 1985 & 2004.82 & 2004.25 \\
\hline 1986 & 2413.96 & 2491.28 \\
\hline 1987 & 2447.69 & 2562.23 \\
\hline 1988 & 2478.59 & 2604.95 \\
\hline 1989 & 2664.9 & 2823.78 \\
\hline 1990 & 2937.1 & 3083.59 \\
\hline 1991 & 3149.48 & 3386.62 \\
\hline 1992 & 3483.37 & 3742.2 \\
\hline 1993 & 4348.95 & 4642.3 \\
\hline
\end{tabular}




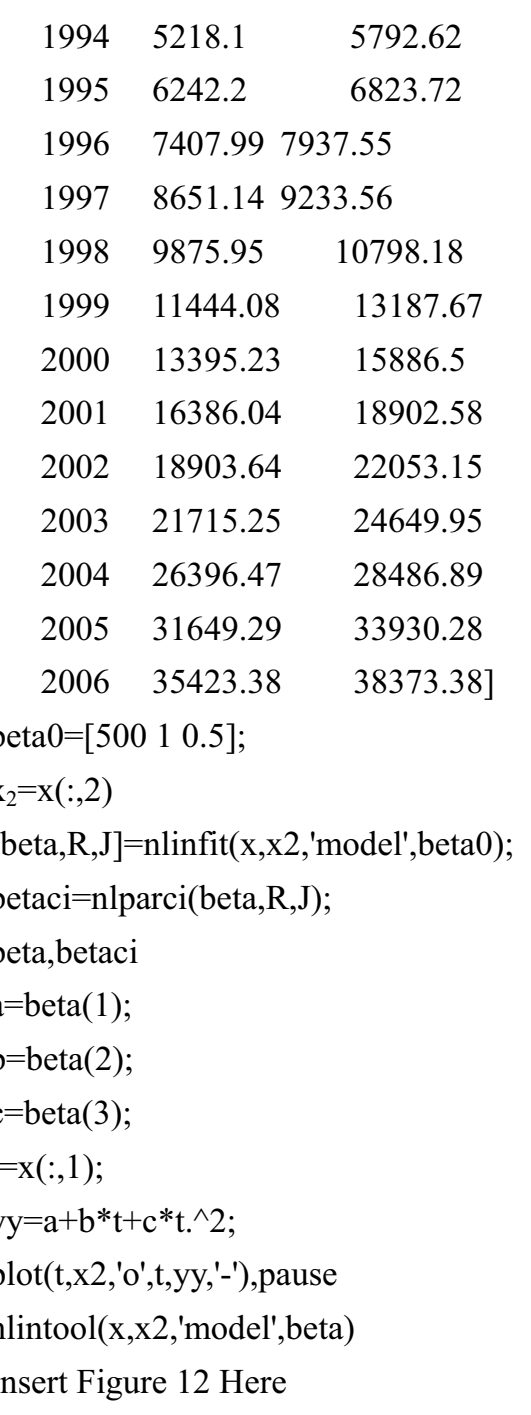

Figure12shows 1978 to $2006 \mathrm{t}$ the time and the plot of fiscal revenue, the line shows the relation between time $\mathrm{t}$ and financial income after the fitting, Figure 13is received interactive screen.

Insert Figure 13 Here

By running the program, we got the relationship between $x_{1}$ and time $t$ as follows:

$x_{1}=5088.674-1000.588 \times \mathrm{t}+72.356 \times \mathrm{t}^{2}$;

Therefore, results of the analysis of time $\mathrm{t}$ and $\mathrm{x} 1$ are showed as Table 12

Insert Table 12 Here

Insert Figure 14, Figure 15 Here

By running the program, we got the relationship between $\mathrm{x} 2$ and $\mathrm{t}$ as follows:

$$
x_{2}=5367.056-1123.257 \times \mathrm{t}+79.050 \times \mathrm{t}^{2} ;
$$

In the same way, the results of the analysis between $\mathrm{x}_{2}$ and $t$ are showed as Table 13

Insert Table 13 Here

3.2 Estimated results:

Administrative budget of 2008:

Substisute $\mathrm{t}=30$ into Model 2, and we can get the following results: $x_{1}=5088.674-1000.588 \times 30+72.356 \times 30^{2}=40191$

$$
x_{2}=5367.056-1123.257 \times 30+79.050 \times 30^{2}=42814
$$


Then substitute the value of $x_{1}, x_{2}$ into (2), and the administrative budget of 2008 is available:

$y=-141.6291-0.2504 \times 40191+0.4538 \times 42814=9223.6$

Administrative budget of 2020:

Substitute $\mathrm{t}=42$ into Model 2, the result is: $x_{1}=5088.674-1000.588 \times 42+72.356 \times 42^{2}=90700$

$$
x_{2}=5367.056-1123.257 \times 42+79.050 \times 42^{2}=97634
$$

Then substitute the value of $x_{1}, x_{2}$ into (2), and the administrative budget of 2020 is available:

$y=-141.6291-0.2504 \times 90700+0.4538 \times 97634=21454$

Administrative budget of 2050:

Substitute $\mathrm{t}=72$ into Model 2, the result is: $x_{1}=5088.674-1000.588 \times 72+72.356 \times 72^{2}=308140$

$$
x_{2}=5367.056-1123.257 \times 30+79.050 \times 30^{2}=334290
$$

Then substitute the value of $x_{1}, x_{2}$ into (2), and the administrative budget of 2050 is as follows:

$y=-141.6291-0.2504 \times 308140+0.4538 \times 334290=704400$

To sum up:the expected administrative costs of 2008 is: 922.36 billion

the expected administrative costs of 2020 is:2145.4billion

the expected administrative costs of 2050 is:70440billion

\section{Governance Ideas of Chinese Government's Administrative Costs}

According to the research result, we believe that the administrative costs of the past Chinese government have always been in the state of blind obedience and lack of scientific assessment standards. So, based on the research result and practical situation, we put forward our idea of governance here.

\subsection{Respect for the scientific principles to identify administrative costs budget standards}

Although the reform of the budget is an administrative manage and technical issue, a sound budget can not only has a far-reaching impact on a country's economic growth, but also is the key element of a good governance structure. Administrative costs of government expenditure are fully integrated into the annual budget, making the control of the administrative cost very subjective initiative. In the past, the government was on consistent respect for the traditional budget work in each year's total expenditure, however, the Government does not has a relatively mature budget or assessment standards on its own administrative expenses. Generally speaking, the administrative cost is not very volatile under a conventional circumstance, thus making it possible to formulate an appropriate scientific expenditure. The forecast above is just a method of setting budget for administrative costs, though we can not say that it is entirely on the scientific significance, it can find an appropriate standards or find an appropriate reference for the future administrative costs. We can take this principle and consider the appropriate adjustment factors well as the actual situation to make the Government's administrative costs more scientific and rational. For instance, according to the data of the past 30 years, we measured Chinese Government's administrative costs in 2008 should be 922.36 billion Yuan, and 2020 and 2050, it should be respectively 2.1454 trillion Yuan and 70.44 trillion Yuan. Perhaps such long-term forecasts as the 2050's also need a further adjustment of the factor to make it more realistic, however, judging from the recent situation, this prediction is still of very good reference value. To a certain extent, to Respect the scientific principles to regulate the administrative costs of the budget standards is an effective way of rigidly bound government's management initiatives and the only way to build entrepreneurs, to integrate different systems and provide seamless services, and promote modernization of the Chinese Government and public administration to be a service-oriented government.

\subsection{Refer to socio-economic development indicators to establish the standards of administrative costs}

In fact, many aspects of public management can be considered together. We assume in the conventional environment, the own share of the size of costs of a relatively Pareto government should be controlled within the scope of the pace of development in their performance, so we believe that the following are indicators which the Government must consider when making budget for administrative costs: First, government administration costs can not be higher than the growth 
rate of the country's whole GDP growth rate; Second, the growth rate of the administrative costs of government expenditure should not be higher than the per capita net income growth rate; Third, the growth rate of administrative costs should not be higher than that of the whole society's consumption growth rate (If we consider more carefully, it should be no higher than the growth rate of the total consumption of the whole society, removing the building, education, culture, health and other necessities of life consumption), it should be said that the indicator is the reference to the target of the administrative costs; Fourth, the growth rate of administrative costs should not be higher than the growth rate of total national income. In addition, we can also consider the relationship between the administrative costs of government expenditures and the financial revenues. In short, only when a standard reference to the expenditure is established, the administrative cost of the budget is scientific. If they can not establish a scientific standard of expenditure for government administrative costs, administration and management is likely to cost more and deviate from the objective basis for the budget. For example, since 1978, the proportion between the Chinese government's administrative and financial costs and the total revenue is a process of sustained growth, that is, from the 1978 administrative costs of the total income of 4.71 percent to the development of administrative costs and expenditures in 2006 accounted for the total income of $19.46 \%$. If accordingly develop, it is the unimaginable.

\subsection{Combine the Government Performance and administration costs together}

In the private sphere, cost-effective means the ratio between GDP and the cost of production. Using

that formula: Economic benefits $=(\mathrm{GDP} /$ production costs $)=\frac{C+V+M}{C+V}$

$\mathrm{C}$ here for the consumption of raw materials; $\mathrm{V}$ is the wages of workers; $\mathrm{M}$ is profit.

In the field of management, the definition of performance is actually not very clear. We believe that the so-called Government Performance is the ratio between management decisions for the welfare of the community and the size of their pay, this price is the administrative cost, and the cost of such administrative expenses in the budget and government performance is closely linked. Western countries developed Entrepreneurial Budget System in the development of the recycling process of government. It is difficult to draw merits of the Government Performance if we do not consider the cost of government administration but just unilaterally emphasize the Government performance. Up to now, it is a co-existent problem that, whether public management practice or theoretical research, they do not closely combine the government performance evaluation with the government administrative costs. We assume that the management does not care about the costs, in the specific tangible public goods that might outweigh the project, and so is the case with intangible public good project. For instance, the history of massive land reclamation in the western region farm, resulting in the present and the future of the desertification phenomenon for a long time and the cost of recycling economy may be greater than the total social welfare. Therefore, how to organically analysis the Government Performance and administrative costs is the problem of security significance of the issue in the area of administrative costs.

\subsection{Reinventing the business processes of Government management}

Reinventing the business processes of Government management is to concern about government actions with management philosophy, which is the key to manage the increasingly diversity of administrative costs. Under the business process of traditional Chinese government management, the focus is to consider how to implement the government's political intentions rather than the cost, as long as the basic organizational form of government is to protect public interest. Fundamentally speaking, management is believed to fulfill the implementation if the business process of management is thought to have achieved the intended impact. The business process of management which came into being under the management philosophy of the government is, to a certain extent, neglects to consider the administrative costs. The concept of public service established by the government in managing business processes fundamentally rejected the government's traditional thought of just considering their own power rather the social needs. Public services under the government's management philosophy are to set up business process of community management. And government's objective value shifts from the vernacular form of government to the scope of protection extended to all public, the basic logo is a social Pareto improvement in the allocation of resources, reflecting the public with their taxes paid to the government to purchase the public the services they need and the administrative costs become the prerequisite for the operation. In fact, the new business processes should follow the four basic processes in the operation of governmental organizations, i.e. the allocation process, the integration process, border exchange process and the process of social motives. Therefore, reshaping the business processes of management is complementarily, mutually reinforced with the control of administrative costs.

\section{References}

Dennis C. (1999). Mueller,Public Choice Theory. P388-P40, translated by Yang Chunxue. Beijing: China Social Science Press.04

Ram,Rati. Government Size and Economic Growth:A New Framework and Some Evidence from Cross-Section and 
Time-Series Data. P191-P203, American Economic Review, Vol.76.

Richard A. Posner. (1975). Social Costs of Monopoly and Regulation, P807-P828, Journal of Political Economy, Vol.83, No.4.

Rubinson Richard. (1977). Dependency Government Revenue and Economic Growth,P.3-P28, Studies in Comparative International Development, 12.

Wuchang Zhang. (2000). Economic Explanation P479-P488: Selected Papers of Steven N. S. Cheung. The Commercial Press, Peking

Xiangzhou He. (2001). Analysis of Government Cost. Xinhua Digest, Dec.

Table 1. Actual implementation of budget cost of China from 1978 to 2006

\begin{tabular}{|c|c|c|c|c|c|c|c|}
\hline \multirow[b]{2}{*}{ Year } & \multirow{2}{*}{$\begin{array}{c}\begin{array}{c}\text { Financial } \\
\text { income }\end{array} \\
\text { (100million) }\end{array}$} & \multirow{2}{*}{\begin{tabular}{|c|}
$\begin{array}{c}\text { Financial } \\
\text { expenditure }\end{array}$ \\
(100million)
\end{tabular}} & \multirow{2}{*}{$\begin{array}{c}\begin{array}{c}\text { Balance of } \\
\text { payments }\end{array} \\
\text { (100million) }\end{array}$} & \multicolumn{2}{|c|}{ Growth rate $(\%)$} & \multicolumn{2}{|c|}{ Administrative expenditure } \\
\hline & & & & $\begin{array}{c}\text { Financial } \\
\text { income }\end{array}$ & $\begin{array}{c}\text { Financial } \\
\text { expenditure }\end{array}$ & Expenditure & $\begin{array}{l}\text { proportion of } \\
\text { administrative } \\
\text { expenses }(\%)\end{array}$ \\
\hline 1978 & 1132.26 & 1122.09 & 10.17 & 29.51 & 33 & 52.9 & 4.71 \\
\hline 1979 & 966.61 & 1281.37 & -314.76 & 1.20 & 28.05 & 70.88 & 5.53 \\
\hline 1980 & 1159.93 & 1228.83 & -68.9 & 1.21 & 1.25 & 75.53 & 6.15 \\
\hline 1981 & 1415.15 & 1426.22 & -11.07 & 12.20 & 16.06 & 76.17 & 7.99 \\
\hline 1982 & 1478.68 & 1482.32 & -3.64 & 4.50 & 3.93 & 102.33 & 6.90 \\
\hline 1983 & 1519.36 & 1556.88 & -37.52 & 2.75 & 5.03 & 158.62 & 10.18 \\
\hline 1984 & 1563.76 & 1647.49 & -83.73 & 2.92 & 5.82 & 161.08 & 9.78 \\
\hline 1985 & 2004.82 & 2004.25 & 0.57 & 22.01 & 17.81 & 171.06 & 8.53 \\
\hline 1986 & 2413.96 & 2491.28 & -77.32 & 20.41 & 24.30 & 214.54 & 8.61 \\
\hline 1987 & 2447.69 & 2562.23 & -114.54 & 1.39 & 28.48 & 268.59 & 10.48 \\
\hline 1988 & 2478.59 & 2604.95 & -126.36 & 1.26 & 1.67 & 301.36 & 11.57 \\
\hline 1989 & 2664.9 & 2823.78 & -158.88 & 13.11 & 13.26 & 386.26 & 13.68 \\
\hline 1990 & 2937.1 & 3083.59 & -146.49 & 10.21 & 9.18 & 414.56 & 13.44 \\
\hline 1991 & 3149.48 & 3386.62 & -237.14 & 7.19 & 9.77 & 414.01 & 12.23 \\
\hline 1992 & 3483.37 & 3742.2 & -258.83 & 10.56 & 10.45 & 463.41 & 12.38 \\
\hline 1993 & 4348.95 & 4642.3 & -293.35 & 24.76 & 24.12 & 634.26 & 13.66 \\
\hline 1994 & 5218.1 & 5792.62 & -574.52 & 20.10 & 24.80 & 847.68 & 14.63 \\
\hline 1995 & 6242.2 & 6823.72 & -581.52 & 19.59 & 17.78 & 996.54 & 14.6 \\
\hline 1996 & 7407.99 & 7937.55 & -529.56 & 18.68 & 16.23 & 1185.28 & 14.93 \\
\hline 1997 & 8651.14 & 9233.56 & -582.42 & 16.79 & 16.33 & 1358.85 & 14.72 \\
\hline 1998 & 9875.95 & 10798.18 & -922.23 & 14.22 & 16.87 & 1600.27 & 14.82 \\
\hline 1999 & 11444.08 & 13187.67 & -1743.59 & 15.88 & 22.12 & 2020.6 & 15.32 \\
\hline 2000 & 13395.23 & 15886.5 & -2491.27 & 17.01 & 20.48 & 2768.22 & 17.43 \\
\hline 2001 & 16386.04 & 18902.58 & -2516.54 & 22.26 & 19.10 & 3512.49 & 18.63 \\
\hline 2002 & 18903.64 & 22053.15 & -3149.51 & 15.37 & 16.66 & 4101.32 & 18.6 \\
\hline 2003 & 21715.25 & 24649.95 & -2934.70 & 14.85 & 11.78 & 4691.26 & 19.03 \\
\hline 2004 & 26396.47 & 28486.89 & -2090.42 & 21.56 & 15.75 & 5521.98 & 19.19 \\
\hline 2005 & 31649.29 & 33930.28 & -2280.99 & 19.99 & 19.11 & 6512.34 & 19.38 \\
\hline 2006 & 35423.38 & 38373.38 & -2950.00 & 11.92 & 13.10 & 7779.64 & 19.46 \\
\hline
\end{tabular}

Source of Information:China Statistical Yearbook.China Statistics Press 2006 Edition; CEInet statistical database January 17, 2007. 
Table 2. data collection of dependent variable y

$\mathrm{y}=\left[\begin{array}{lllllllllll}52.9 & 70.88 & 75.53 & 76.17 & 102.33 & 158.62 & 161.08 & 171.06 & 214.54 & 268.59 \\ 301.36 & 386.26 & 414.56 & 414.01 & 463.41 & 634.26 & 847.68 & 996.54 & 1185.28 \\ 1358.85 & 1600.27 & 2020.6 & 2768.22 & 3512.49 & 4101.32 & 4691.26 & 5521.98 \\ 6512.34 & 7779.64\end{array}\right]$

Table 3. data collection of variable $\mathrm{x} 1$

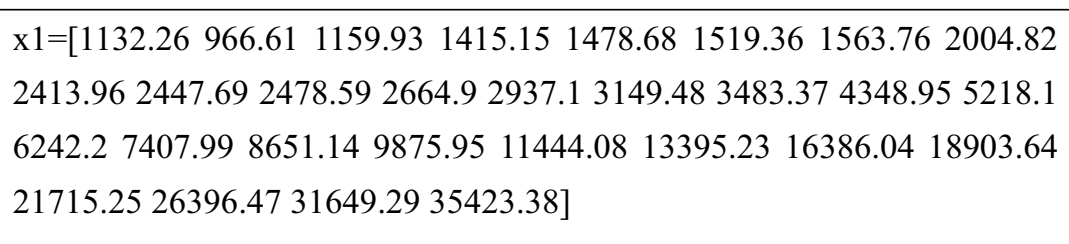

Table 4. data collection of variable $\mathrm{x} 2$

\begin{tabular}{|l}
$\mathrm{x}_{2}=\left[\begin{array}{lllllllll}1122.09 & 1281.37 & 1228.83 & 1426.22 & 1482.32 & 1556.88 & 1647.49 & 2004.25 \\
2491.28 & 2562.23 & 2604.95 & 2823.78 & 3083.59 & 3386.62 & 3742.2 & 4642.3 \\
5792.62 & 6823.72 & 7937.55 & 9233.56 & 10798.18 & 13187.67 & 15886.5 & 18902.58 \\
22053.15 & 24649.95 & 28486.89 & 33930.28 & 38373.38\end{array}\right]$
\end{tabular}

Table 5. data collection of variable $\mathrm{x} 3$

$$
\begin{aligned}
& x_{3}=\left[\begin{array}{llllllllll}
10.17 & -314.76 & -68.9 & -11.07 & -3.64 & -37.52 & -83.73 & 0.57 & -77.32 & -114.54 \\
-123.36 & -158.88 & -146.49 & -237.14 & -258.83 & -293.35 & -574.52 & -581.52 & -529.56 \\
-582.42 & -922.23 & -1743.59 & -2491.27 & -2516.54 & -3149.51 & -2934.7 & -2090.42 \\
-2280.99 & -2950
\end{array}\right]
\end{aligned}
$$

Table 6. data collection of variable $\mathrm{x} 4$

$x 4=\left[\begin{array}{lllllllllllll}29.51 & 1.20 & 1.21 & 12.20 & 4.50 & 2.75 & 2.92 & 22.01 & 20.41 & 1.39 & 1.26 & 13.11 \\ 10.21 & 7.19 & 10.56 & 24.76 & 20.10 & 19.59 & 18.68 & 16.79 & 14.22 & 15.88 & 17.01 & 22.26 \\ 15.37 & 14.85 & 21.56 & 19.99 & 11.92\end{array}\right]$

Table 7. data collection of variable $\mathrm{x} 5$

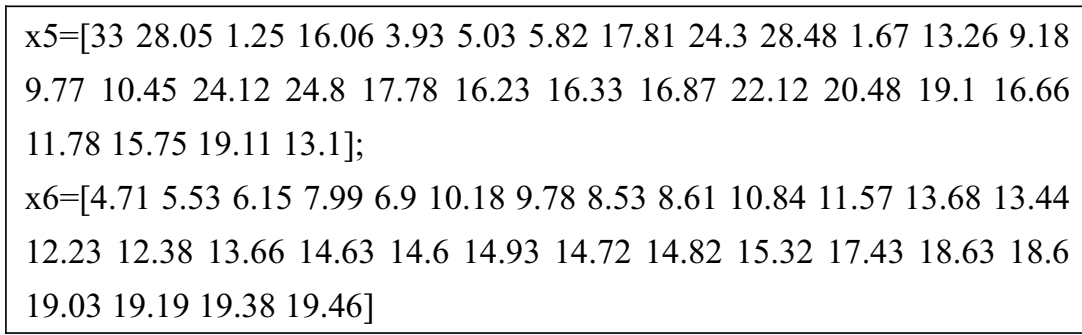


Table 8. data collection of $y$

$\mathrm{Y}=0.1 \times\left[\begin{array}{lllllllll}52.9 & 70.88 & 75.53 & 76.17 & 102.33 & 158.62 & 161.08 & 171.06 \\ 214.54 & 268.59 & 301.36 & 386.26 & 414.56 & 414.01 & 463.41 & 634.26 \\ 847.68 & 996.54 & 1185.28 & 1358.85 & 1600.27 & 2020.6 & 2768.22 \\ 3512.49 & 4101.32\end{array}\right]$

Table 9. data collection of $\mathrm{x}_{1}$

\begin{tabular}{|c|c|}
\hline $\mathrm{x}_{1}=0.1 \times[1132.26$ & $\begin{array}{lllll}966.61 & 1159.93 & 1415.15 & 1478.68 & 1519\end{array}$ \\
\hline 2004.82 & $2447.69 \quad 2478.59 \quad 2664.9$ \\
\hline $3149.48 \quad 3483.37$ & $\begin{array}{lllll}4348.95 & 5218.1 & 6242.2 & 7407.99 & 8651 .\end{array}$ \\
\hline & \\
\hline
\end{tabular}

Table 10. data collection of $\mathrm{x}_{2}$

\begin{tabular}{|llllllll}
\hline $\mathrm{x}_{2}=0.1 \times\left[\begin{array}{lllllll}1122.09 & 1281.37 & 1228.83 & 1426.22 & 1482.32 & 1556.88 \\
1647.49 & 2004.25 & 2491.28 & 2562.23 & 2604.95 & 2823.78 & 3083.59 \\
3386.62 & 3742.2 & 4642.3 & 5792.62 & 6823.72 & 7937.55 & 9233.56 \\
10798.18 & 13187.67 & 15886.5 & 18902.58 & 22053.15\end{array}\right]$ \\
\hline
\end{tabular}

Here , $\mathrm{n}=25, \mathrm{~m}=2$

$\mathrm{X}=\left[\operatorname{ones}(\mathrm{n}, 1), \mathrm{x} 1^{\prime}, \mathrm{x} 2{ }^{\prime}\right]$

[b,bint,r,rint,s] $=\operatorname{regress}\left(\mathrm{Y}^{\prime}, \mathrm{X}, 0.05\right)$

b, bint,r,rint,s,

The operation results are shown in Table 11:

Table 11. operation results of $\hat{\beta}_{0}, \hat{\beta}_{1}, \hat{\beta}_{2}$

\begin{tabular}{|l|l|l|}
\hline $\begin{array}{l}\text { Regression } \\
\text { coefficient }\end{array}$ & confidence interval of regression coefficient & $\begin{array}{l}\text { The estimated value of } \\
\text { regression coefficient }\end{array}$ \\
\hline$\beta_{0}$ & {$\left[\begin{array}{ll}-210.4264 & -72.8317\end{array}\right]$} & -141.6291 \\
\hline$\beta_{1}$ & {$\left[\begin{array}{ll}-0.4468 & -0.0939\end{array}\right]$} & -0.2704 \\
\hline$\beta_{2}$ & {$\left[\begin{array}{ll}0.2674 & 0.5691\end{array}\right]$} & 0.4182 \\
\hline$R^{2}=1$ & $F=2005.8$ & $p<0.0001$ \\
\hline
\end{tabular}

Table 12. The results of the analysis marked with $\mathrm{x} 1$

\begin{tabular}{|l|ll|}
\hline Coefficient & Interval of the value of the coefficient & Estimated value of coefficient \\
\hline$\beta_{0}$ & {$\left[\begin{array}{ll}2785.782 & 7391.566\end{array}\right]$} & 5088.674 \\
\hline$\beta_{1}$ & {$\left[\begin{array}{ll}-1546.264 & -838.588\end{array}\right]$} & -1192.426 \\
\hline$\beta_{2}$ & {$\left[\begin{array}{ll}60.911 & 83.801\end{array}\right]$} & 72.356 \\
\hline
\end{tabular}

In the same way,we can get the relationship between $\mathrm{x} 2$ and $\mathrm{t}$

Table13. The results of the analysis marked with $\mathrm{x} 2$

\begin{tabular}{|l|ll|}
\hline Coefficient & Interval of the value of the coefficient & Estimated value of coefficient \\
\hline$\beta_{0}$ & {$\left[\begin{array}{ll}3181.663 & 7552.449\end{array}\right]$} & 53670.56 \\
\hline$\beta_{1}$ & {$\left[\begin{array}{ll}-1620.442 & -9488.73\end{array}\right]$} & -1284.657 \\
\hline$\beta_{2}$ & {$\left[\begin{array}{ll}68.188 & 89.911\end{array}\right]$} & 79.050 \\
\hline
\end{tabular}


Secondly,according to the information we can draw plots of Y with X1, X2 see Figure 1, Figure 2. $\operatorname{plot}\left(\mathrm{x} 1, \mathrm{y},{ }^{\prime *}\right) ; \operatorname{plot}\left(\mathrm{x} 2, \mathrm{y},{ }^{\prime * \prime}\right)$

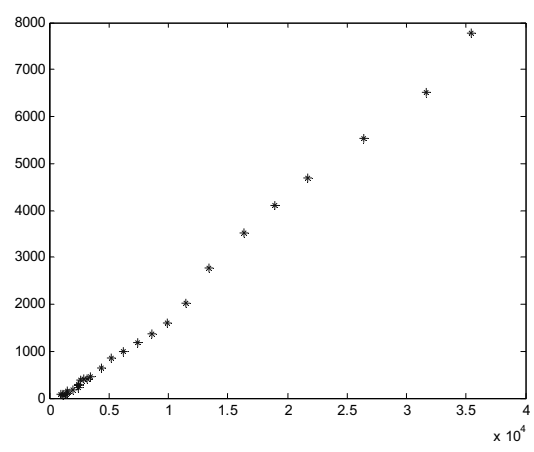

Figure 1. (plot between $\mathrm{y}$ and $\mathrm{x} 1$ )

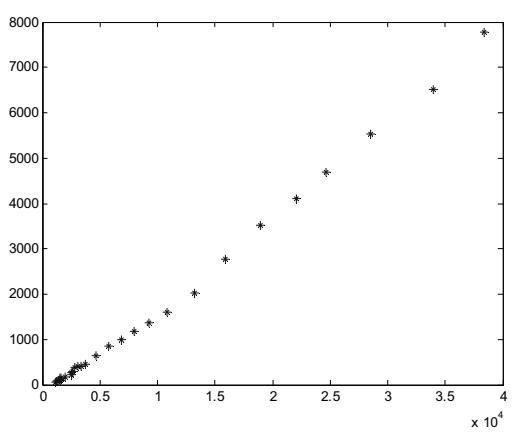

Figure 2. (plot between $\mathrm{y}$ and $\mathrm{x} 2$ )

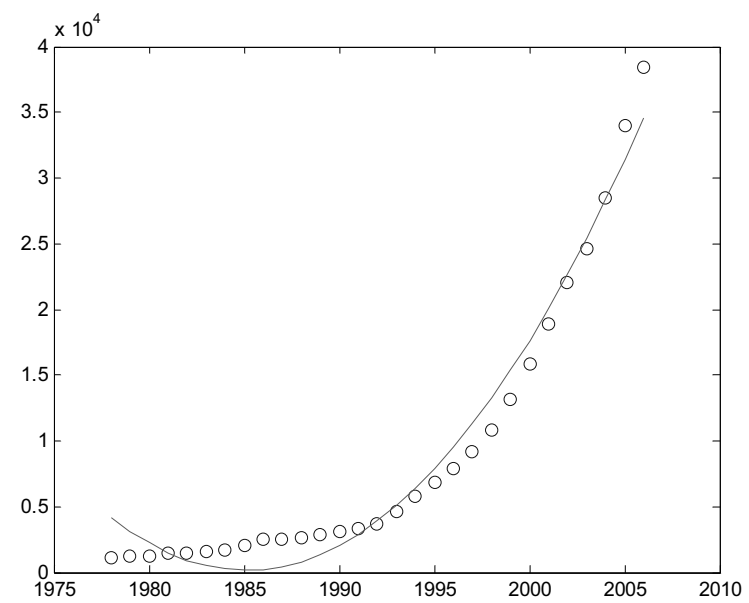

Figure12. Signs of the 1978-2006 financial income plots

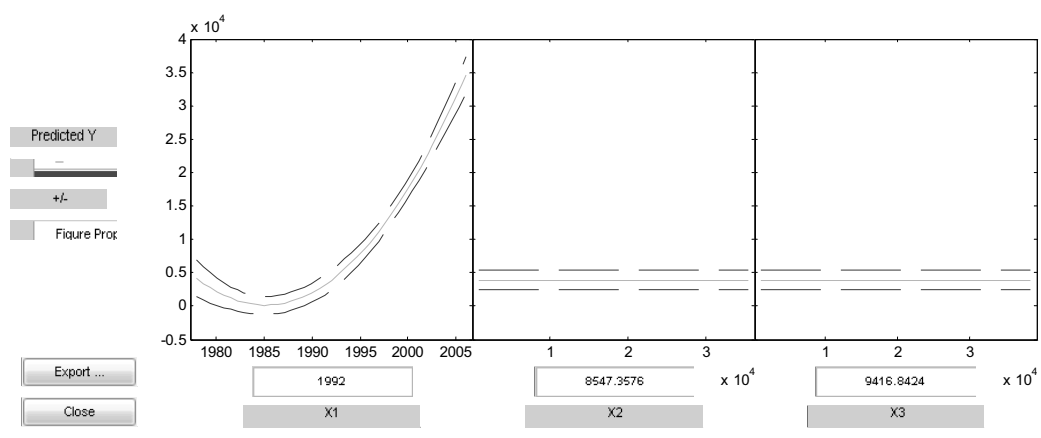

Figure13. the interactive screenof the signs of the 1978-2006 fiscal revenue 


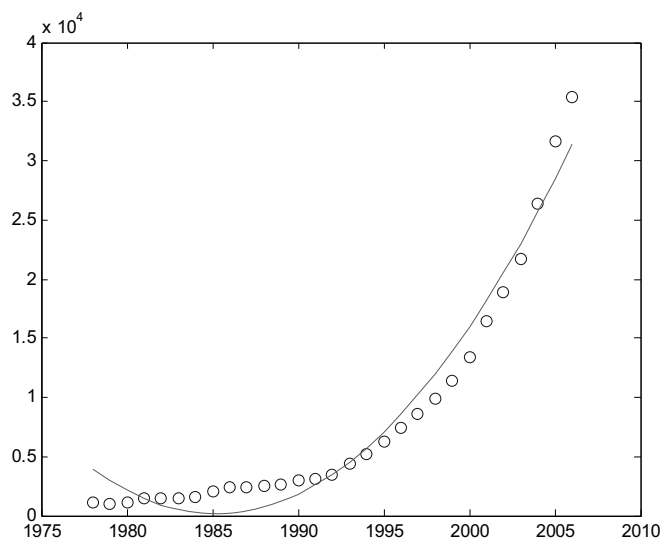

Figure 14. Financial scattergraph of 1978-2006 marked with x2

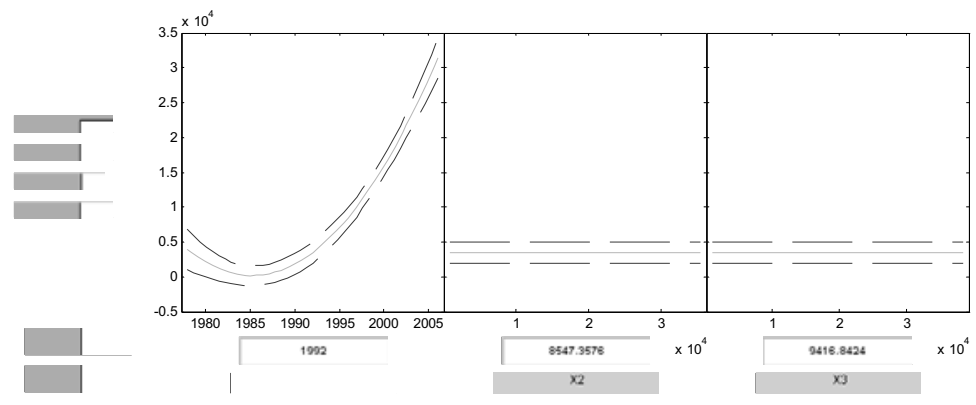

Figure 15. 1978-2006 financial income interactive screen of 1978-2006 marked with x2 